\title{
Perbandingan Pemahaman Seks Anak Usia 4-5 Tahun Ditinjau dari Penerapan Pendidikan Seks
}

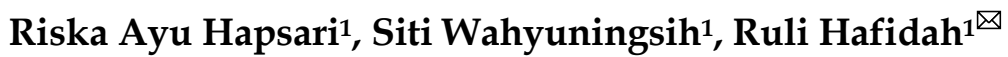 \\ Pendidikan Guru Pendidikan Anak Usia Dini, Universitas Sebelas Maret, Indonesia(1) \\ DOI: $\underline{10.31004 / \text { obsesi.v6i3.1363 }}$
}

\begin{abstract}
Abstrak
Pendidikan seks prasekolah TK dan RA untuk memfasilitasi perkembangan anak termasuk pemahaman seks yang komprehensif. RA memiliki jenjang seperti TK namun berbasis islam dengan pendekatan yang memadukan iman sekaligus amal saleh. Tujuan penelitian untuk mengetahui perbandingan pemahaman seks pada aspek kognitif dan sosem di TK dan RA. Desain penelitian ini kuantitatif komparasi. Sampel penelitian 30 anak usia 4-5 tahun di TK Garuda dan RA Al-Kautsar, Surakarta. Teknik pengumpulan data melalui kuesioner tingkat pemahaman seks anak dengan. Temuan baru penelitian dari hasil rekapitulasi kuesioner menunjukan perbedaan nilai yang signifikan. Hipotesis mengenai perbedaan pemahaman seks anak usia 4-5 tahun aspek kognitif dan sosial emosi diterima. Pemahaman seks di Ra lebih unggul karena penerapan pendidikan seks secara islami dimana aspek sosial emosi diperhatikan detil dalam kegiatan belajar. Anak tidak hanya paham kognitifnya saja seperti perbedaan laki-laki dan perempuan, tetapi dapat menghormati dirinya dengan diajari bagaimana melindungi diri dengan menutup aurat, dan merawat diri
\end{abstract}

Kata Kunci: pemahaman seks; pendidikan seks; lembaga tk dan ra; anak usia dini.

\begin{abstract}
Sex education Kindergarden and RA to facilitate children's development includes comprehensive understanding of sex. Ra has a level like kindergarten but is islamic based with an approach that combines both faith and godly charity. Research purposes for figuring out a comparison of sexual understanding in cognitive and spiritual aspects of Kindergarten and RA. The design of this research is quantitative comparative. Research samples of 30 4- 5 yearold children at TK Garuda and RA Al-Kautsar, Surakarta. Data collection techniques through a questionnaire with a child's level of understanding sex. New research results from the cumulative recapitulation of the questionnaire indicate a significant difference in value. Hypotheses regarding the difference in understanding of sex between a 4-year-old child would be acceptable cognitive and social emotional aspects. "Sexual understanding in RA is superior to the islamic application of sexual education where emotional social aspects are considered detailed in learning activities. Not only is the child such a cognitive understanding as the differences between the male and the female, but it can honor him by being taught how to protect himself by shutting the loins, and caring for themself.
\end{abstract}

Keywords: sex understanding; sex education; kindergarten and ra institutions; early childhood.

Copyright (c) 2021 Riska Ayu Hapsari, et al.

$\triangle$ Corresponding author:

Email Address : riskaayu07@student.uns.ac.id (Surakarta, Indonesia)

Received 17 May 2021, Accepted 10 June 2021, Published 26 Desember 2022 


\section{PENDAHULUAN}

Seks dianggap sebagai hal tabu dalam masyarakat khususnya jika diperbincangkan bersama anak-anak sehingga hal tersebut menjadi salah satu faktor anak cenderung diam saat mengalami kekerasan seksual (Andika, 2010; Chasanah, 2018). Seks adalah perbedaan badani atau biologis perempuan dan laki-laki (Sarwono \& Siamsidar, 1986). Andika (2010) menyatakan bahwa seks adalah jenis kelamin antara laki-laki dan perempuan, segala sesuatu mengenai organ reproduksi termasuk cara merawat. Hurlock (1978) menyatakan bahwa semua anak memiliki minat pada seks di setiap tahap perkembangannya, minat ini lebih besar setelah anak masuk sekolah dan berhubungan dengan teman sebaya. Sehingga, seks merupakan jenis kelamin antara laki-laki dan perempuan dan segala sesuatu mengenai organ reproduksi yang pada dasarnya setiap anak sudah memiliki minat sejak dini dan penting untuk diberi edukasi.

Pemahaman mengenai seks pada anak usia dini sangatlah penting. Penelitian yang dilakukan oleh Wu \& Lee (2020), di Taiwan menunjukan bahwa resiko anak yang mengalami pengalaman seks buruk atau pelecehan seks pada usia dini akan mempengaruhi tumbuh kembang anak hingga usia dewasa, dimana anak perempuan telah ditemukan kurang asertif dan memiliki harga diri sedikit lebih rendah daripada anak laki-laki. Selain itu anak perempuan dan laki-laki akan mengalami gejala depresi, kecemasan sosial dan kesepian sosial secara bertahap meningkat dari rentang 9 hingga 18 tahun. Jadi, penanaman pendidikan seks sejak dini sangat penting agar dapat mencegah resiko anak mengalami pengalaman seks buruk atau kekerasan seksual.

Hi.Yusuf (2020) menjelaskan bahwa pendidikan seks merupakan upaya memberikan pemahaman kepada anak sesuai dengan usianya mengenai fungsi organ kelamin dan mengenai bimbingan menjaga dan memelihara organ kelamin mereka. Pendidikan seks juga berhubungan dengan upaya pengajaran, penyadaran, dan pemberian informasi tentang masalah seksual. Informasi yang diberikan di antaranya pengetahuan tentang fungsi organ reproduksi dengan menanamkan moral, etika, komitmen, agama agar tidak terjadi "penyalahgunaan" organ reproduksi tersebut. Pendidikan seks itu sangat penting diberikan sejak dini. Pengetahuan tentang seks pada anak-anak dapat mencegah terjadinya penyimpangan seksual pada anak (Ratnasari \& Alias, 2016). Chomaria (2012) menyatakan bahwa pendidikan seks yang baik dapat membantu anak mempersiapkan diri menuju individu dewasa yang mandiri. Sehingga orangtua dan guru memiliki peranan penting untuk mencegah terjadinya pengalaman buruk atau kekerasan seksual terhadap anak dengan memberikan pendidikan seks sejak dini. Solehuddin (Susanto, 2017) menyatakan bahwa program pendidikan prasekolah merupakan suatu upaya memfasilitasi perkembangan anak yang sifatnya komprehensif dan menyeluruh, serta memberikan pengaruh yang sangat fundamental bagi optimalisasi aspek perkembangan anak. Namun, hasil penelitian yang dilakukan oleh Justicia (2017) yang didukung dengan data penelitian Rahmawati (2012) menunjukan bahwa masih terdapat 16 anak dari 20 responden di Aceh yang tidak mendapat pengetahuan seks. Sehingga persentase kurangnya pemahaman seks pada anak usia dini cukup tinggi.

Bentuk pendidikan seks di lembaga Pendidikan Anak Usia Dini (PAUD) berbedabeda, tidak terkecuali Taman Kanak-Kanak (TK) dan Raudhatul Athfal (RA). TK memiliki empat pokok pendidikan seks yaitu mengenalkan anatomi bagian tubuhnya, membangun kebiasaan positif yang melibatkan anggota tubuh seperti tidak berganti baju ditempat umum, menanamkan pentingnya menjaga organ tubuh tertentu, dan membiasakan anak berpakaian seusai identitas kelaminnya (Jatmikowati dkk., 2015).

Berbeda dengan TK, RA menerapkan tiga pokok pendidikan seks yaitu menanamkan jiwa maskulinitas pada anak laki-laki dan jiwa feminitas pada anak perempuan dengan acuan hadits riwayat Al. Bukhari yaitu Ibnu Abbas berkata: Rasulullah SAW melaknat laki-laki yang berlagak wanita dan wanita yang berlagak meniru laki-laki, mendidik menjaga kebersihan alat kelamin dari najis, dan menanamkan rasa malu supaya menjadi manusia yang bermoral 
(Amirudin \& Nirmala, 2018). Tiga pokok tersebut diterapkan dengan metode pengajaran islam menurut Dacholfany \& Hasanah (2018) terdapat lima macam, yaitu: metode pendidikan melalui teladan, nasihat, cerita, kebiasaan, dan peristiwa.

Berdasarkan uraian latar belakang di atas, maka peneliti ingin melakukan penelitian mengenai perbandingan tingkat pemahaman seks anak usia 4-5 tahun di TK dengan di RA untuk mengetahui adakah perbedaan signifikan tingkat pemahaman seks anak antara kedua bentuk layanan PAUD tersebut, yang akan dirumuskan dalam judul "Perbandingan Pemahaman Seks Anak Usia 4-5 Tahun Ditinjau Dari Penerapan Pendidikan Seks di Taman Kanak-kanak dan Raudhatul Athfal“.

\section{METODOLOGI}

Penelitian dilaksanakan di TK Negeri Garuda dan RA Al-Kautsar Surakarta pada kelompok A yang berusia 4-5 tahun. Penelitian ini merupakan penelitian kuantitatif dengan jenis penelitian komparasi. Sukmadinata (2009) mengungkapkan bahwa penelitian komparasi merupakan penelitian yang diarahkan untuk mengetahui apakah antara dua variabel atau lebih dari dua kelompok ada perbedaan dalam aspek atau variabel yang ingin diteliti. Kelompok yang akan dibandingkan adalah kelompok TK dan RA. Sampel dalam penelitian ini adalah peserta didik usia 4-5 tahun di TK Negeri Garuda Surakarta yang berjumlah 15 anak dan RA Al-Kautsar Surakarta yang berjumlah 15 anak pula. Sampel yang digunakan adalah seluruh populasi yang ada yaitu 24 anak juga.

Teknik pengumpulan data menggunakan kuesioner untuk mengetahui tingkat pemahaman seks pada ada dan materi pendidikan seks yang diterapkan di lembaga PAUD tersebut. Kuesioner penilaian akan ditujukan untuk mengetahui data tingkat pemahaman seks anak pada usia 4-5 tahun. Pertanyaan pada kuesioner penilaian mengacu pada perkembangan aspek kognitif dan sosial emosional yang berkaitan dengan pemahaman seks anak. Masingmasing poin penilaian akan diberikan 4 jenis jawaban yang merupakan rating scale 1-4 dengan spesifikasi BB: Belum Berkembang (1), MB: Mulai Berkembang (2), BSH: Berkembang Sesuai Harapan (3), BSB: Berkembang Sangat Baik (4). Kuesioner penilaian perkembangan pemahaman seks diadaptasi berdasarkan pendapat Chomaria (2012), dan Andika (2010) mengenai tahapan perkembangan seks pada anak usia 4-5 tahun, ditegaskan dengan Permendikbud No. 137 Tahun 2014 Tentang Standar Nasional Pendidikan Anak Usia Dini dan Keputusan Menteri Agama No. 792 Tahun 2018 Tentang Pedoman Implementasi Kurikulum Raudhatul Athfal (RA).

Tabel 1 Kisi-kisi Penilaian Indikator Pemahaman Seks Anak Usia 4-5 Tahun

\begin{tabular}{|c|c|c|}
\hline No & Aspek & Indikator \\
\hline 1. & $\begin{array}{l}\text { Mengenal nama anggota tubuh beserta } \\
\text { fungsinya (Kog) }\end{array}$ & $\begin{array}{l}\text { menyebutkan dan menunjukan } 4 \text { nama anggota } \\
\text { tubuh beserta fungsinya }\end{array}$ \\
\hline 2. & $\begin{array}{l}\text { Mengetahui perbedaan laki-laki dan } \\
\text { perempuan berdasarkan fisik yang } \\
\text { tampak. (Kog) }\end{array}$ & $\begin{array}{l}\text { menyebutkan } 4 \quad \text { perbedaan laki-laki } \\
\text { perempuan berdasarkan fisik yang tampak. }\end{array}$ \\
\hline 3. & $\begin{array}{l}\text { Mengetahui asal usul bayi dalam } \\
\text { kandungan ibu. (Kog) }\end{array}$ & $\begin{array}{l}\text { mengurutkan } 5 \text { tahapan asal usul bayi dalam } \\
\text { kandungan ibu dengan benar. }\end{array}$ \\
\hline 4. & $\begin{array}{l}\text { Menjaga area sensitif dan privasi pada } \\
\text { tubuh (Sosem) }\end{array}$ & $\begin{array}{l}\text { menunjukan } 3 \text { area sensitif dan privasi pada } \\
\text { tubuh (yang tidak boleh disentuh orang lain). }\end{array}$ \\
\hline 5. & $\begin{array}{l}\text { Bersikap mandiri dalam menjaga dan } \\
\text { merawat tubuh (Sosem) }\end{array}$ & $\begin{array}{l}\text { sikap mandiri dalam menjaga dan merawat tubuh } \\
\text { (alat kelamin setelah buang air) melalui boneka } \\
\text { tangan. }\end{array}$ \\
\hline
\end{tabular}

Peneliti akan menggunakan teknik pengambilan sampel dengan sample random dimana teknik penentuan dan pengambilan sampel pada masing-masing populasi memiliki probabilitas yang sama untuk dipilih menjadi sampel. Jumlah sampel penelitian ini dalam 
populasi anak usia 4-5 tahun adalah 30 anak dengan masing-masing sekolah maksimal 15 anak oleh setiap satu guru di kelas. Hal ini berdasarkan pada pendapat Borg \& Gall (1983) yang menyebutkan bahwa penelitian komparasi diperlukan 15-30 responden setiap kelompok. Penilaian dalam penelitian ini dilakukan melalui teacher report dimana kuesioner diisi oleh guru kelas. Teknik analisis data yang digunakan adalah uji prasyarat analis menggunakan uji normalitas dan homogenitas dan uji hipotesis menggunakan independent sample t-test untuk mengetahui perbandingan pemahaman seks anak usia 4-5 tahun ditinjau dari penerapan pendidikan seks di TK dan RA dengan bantuan SPSS 22 for window.

\section{HASIL DAN PEMBAHASAN}

Hasil data yang diperoleh dari kuesioner anak yang telah diisi oleh guru, selanjutnya dijumlahkan untuk diolah dan menghasilkan nilai minimal (min), nilai maksimal (max) dan mean atau nilai rata-rata, range serta standar deviasinya. Data yang telah diperoleh dari penelitian ini disajikan pada tabel 1.

Tabel 2. Deskripsi Data

\begin{tabular}{llllll}
\hline & Kelomok & $\mathbf{N}$ & $\boldsymbol{R}$ & $\boldsymbol{M}$ & Std. Dev \\
\hline \multirow{2}{*}{ Nilai Pemahaman Seks } & RA & 15 & 6 & 16,33 & 1,543 \\
& TA & 15 & 8 & 13,60 & 2,261 \\
\hline
\end{tabular}

Berdasarkan tabel 1 dapat dilihat bahwa nilai pemahaman seks dari kedua kelompok dengan $\mathrm{N}$ (jumlah responden) masing-masing adalah 15. Range menunjukkan rentang nilai maksimum dan minimum pada masing-masing kelompo. Mean menunjukkan rata-rata nilai pemahaman seks diantara kedua kelompok dan standar deviasi menunjukkan variasi sebaran data pada masing-masing kelompok.

\section{Hasil Uji Prasyarat Analisis Uji Normalitas}

Hasil uji normalitas menunjukkan tingkat signifikansi data kuesioner kelompok RA dan TK yang didapatkan dari hasil uji normalitas di atas yaitu sebesar 0,200. Berdasarkan data tersebut dapat disimpulkan bahwa kedua data hasil uji normalitas memperoleh nilai signifikansi lebih dari 0,05, sehingga data tersebut berdistribusi normal, dan dapat dinyatakan telah memenuhi syarat normalitas normal (Sujarweni, 2014). Data berdistribusi normal berarti data pemahaman seks dapat diukur.

\section{Uji Homogenitas}

Hasil uji homogenitas menunjukkan bahwa nilai signifikansi uji homogenitas pemahaman seks sebesar 0,132. Berdasarkan data tersebut, dapat disimpulkan bahwa kedua data memenuhi syarat sebagai data yang homogen dengan tingkat signifikansi $p>0,05$. Hal tersebut berarti bahwa data-data penelitian memiliki variasi data yang sama sehingga kumpulan data yang akan diukur berasal dari populasi yang homogen dan selanjutnya dapat dilakukan perbandingan untuk mengetahui hasil perbandingan pemahaman seks anak di TK dan RA.

\section{Hasil Uji Hipotesis \\ Independent Sample T-Test}

Hasil uji independent sampe t-test menunjukkan bahwa nilai pemahaman seks yang diperoleh kelompok RA dan TK memiliki nilai signifikansi angka lebih besar dari 0,05 yaitu sebesar 0,001 yang artinya terdapat perbedaan yang signifikan antara kelompok RA dan TK. Hasil uji tersebut menunjukkan bahwa hipotesis mengenai terdapat perbedaann pemahaman seks anak usia 4-5 tahun ditinjau dari penerapan pendidikan seks di TK dan RA diterima 
karena nilai signifikansi angka kurang dari 0,05 yaitu sebesar 0,001. Nilai mean kelompok RA juga lebih besar 2,73 dari kelompok TK yang memperjelas bahwa nilai pemahaman seks anakanak di kelompok RA lebih tinggi daripada anak-anak di kelompok TK.

Hasil penelitian menunjukkan bahwa pemahaman seks pada kelompok RA lebih unggul daripada kelompok TK. Hal tesebut dapat dibuktikan dengan adanya selisih mean pada kelompok RA lebih besar 2,73 daripada kelompok TK. Perbedaan tersebut dipengaruhi oleh pemahaman seks pada kelompok RA di RA Al-Kautsar yang diajarkan tidak hanya pengetahuannya saja, tetapi bagaimana cara menjaga dan merawatnya pula. Berdasarkan wawancara yang telah dilakukan, pemahaman seks di RA Al-Kautsar dikemas secara islami. Anak-anak tidak hanya diajarkan bagian-bagian tubuh seperti alat kelamin dan yang tidak boleh disentuh oleh orang lain, tetapi juga bagaimana menjaga aurat sebagai umat muslim dan tetap menerapkan pemahaman seks pada anak. Hal ini sejalan dengan pendapat Camelia \& Nirmala (2017) yang menyatakan bahwa pendidikan seksual atau seks Islami dapat dimaknai sebagai upaya memberikan pengetahuan tentang aspek-aspeknya, pengertiannya, tujuannya, serta akibatnya yang meliputi bidang biologis, psikologis dan psikososial dengan menanamkan moral etika serta komitmen agama Islam sehingga hormat terhadap diri. Anakanak tidak hanya mengerti secara kognitifnya saja seperti dari mana bayi lahir, perbedaan laki-laki dan perempuan, maupun nama anggota tubuh dan fungsinya, tetapi dapat menghormti dirinya sendiri dengan diajari bagaiman melindungi diri dengan menutup aurat, merawat diri, dengan tetap mengetahui bagian-bagian tubuh yang tidak boleh disentuh oleh orang lain

Keunggulan pemahaman seks dalam kemasan Islami yang diajarkan di RA Al-Kautsar adalah pembiasaan yang dilakukan. Anak-anak dibiasakan memakai pakaian muslim dan muslimah yang dapat melindungi dirinya, dan malu jika bepergian tidak menutup auratnya. Anak-anak juga dibiasakan toilet training, dengan pembiasaan di kamar mandi sesuai adab Islam, agar bagian tubuhnya seperti alat kelamin dan dada, dibiasakan bisa dirawat oleh dirinya sendiri sejak dini. Hal tersebut juga sejalan dengan pendapat Amirudin \& Nirmala (2018), yang menyatakan bahwa ketika anak sudah dapat membedakan sesuatu, maka pengawasan harus lebih ditingkatkan lagi yaitu dengan menanamkan sifat malu, ditentang jika memakai pakaian sutera dan berwarna, dijaga dari pergaula, diajarkan batas normanorma agama yang diperlukan. Pembiasaan-pembiasan tersebut juga dapat meningkatkan pendidikan seks pada anak sehingga anak akan lebih memahami batasan akan dirinya sendiri.

Pemahaman seks di TK juga baik adanya. Akan tetapi, berdasarkan hasil kuesioner dan wawancara yang telah dilakukan di TK Garuda, pemahaman seks pada anak di TK tersebut lebih optimal pada pemahaman seks yang berhubungan dengan aspek kognitif. Anak-anak lebih memahami perbedaan laki-laki dan perempuan, mengetahui bagian tubuh dan fungsinya, dan mengetahui asal usul bayi. Anak-anak tetap dibiasakan menjaga dirinya dengan cara berpakaian yang menutupi bagian-bagian tubuhnya yang tidak boleh dilihat dan disentuh oleh orang lain sesuai norma yang berlaku, tetapi tidak seketat pembiasaan seperti RA atau sekolah berbasis Islam yang mewajibkan menutup aurat sejak dini.

Metode dan strategi mengenalkan seks sejak dini antara lain menanamkan rasa malu pada anak, menanamkan jiwa maskulinitas pada anak laki-laki dan feminitas pada anak perempuan, memisahkan tempat tidur mereka ketika usia 7-10 tahun, mengenalkan waktu berkunjung (meminta izin dalam 3 waktu), membekali pendidikan seks dan figh pada anak dalam mendidik menjaga kebersihan alat kelamin, mengenalkan mahramnya, mendidik anak agar selalu menjaga pandangan mata, mendidik anak agar tidak melakukan ikhtilat, mendidik anak agar tidak melakukan khalwat, mendidik etika berhias, mengenalkan anak tentang ihtilam dan haid (Mukti, 2018). Metode pemahaman seks tersebut merupakan metode mengenalkan pemahaman seks secara Islami. Akan tetapi, tetap dapat diterapkan secara umum seperti di TK, dengan menyesuaikan program pembelajaran yang ada di TK tersebut. Metode tersebut memiliki manfaat bagi anak, agar anak dapat melindungi, merawat, dan menjaga dirinya sendiri melalui pemahaman seks yang telah diajarkan dan dibiasakan. 
Yuniarni (2021) menggunakan bussy book berbasis neurosains untuk mengenalkan seks pada anak usia dini, sedangkan Oktarina \& Liyanovitasari (2019) memanfaatkan media gambar dengan tujuan yang sama.

Hasil penelitian menunjukkan bahwa pemahaman seks pada anak-anak kelompok RA lebih unggul daripada anak-anak kelompok TK. Hal tesebut dapat dibuktikan dengan adanya selisih mean pada anak-anak kelompok RA lebih besar 2,73 dari pada anak-anak kelompok TK. Perbedaan tersebut dipengaruhi oleh pemahaman seks pada anak-anak kelompok RA di RA Al-Kautsar yang diajarkan tidak hanya pengetahuannya saja, tetapi bagaimana cara menjaga dan merawatnya pula. Hal tersebut sesuai dengan penelitian yang dilakukan oleh Mukti (2018) yang menjelaskan bahwa teori islam dengan teori barat memiliki perbedaan dalam menanamkan pemahaman seks pada anak, dimana Islam mengatur cara pendidikan melalui kebutuhan manusia yaitu organik, psikologis, spritial, fisik manusia, serta moral pada manusia. Teori barat cenderung berkonsentrasi pada fakta anatomi dan biologis, cenderung mengabaikan beberapa dasar yang terkait dengan martabat manusia.

\section{SIMPULAN}

Terdapat perbedaan pemahaman seks antara anak-anak usia 4-5 tahun di TK dan RA. Penerapan pendidikan seks dilaksanakan di RA dilakukan secara islami dimana aspek sosial emosi lebih tinggi dibanding TK dengan menerapkan lima materi pendidikan seks secara eksplisit atau tertulis dalam RPPH dan tiga materi pendidikan seks secara implisit atau sekedar pembiasaan. Sedangkan di kelompok TK, penerapan pendidikan seks dilakukan secara umum dengan mengedepankan pemahaman seks secara aspek kognitifnya dengan menerapkan lima materi secara eksplisit atau tertulis dalam RPPH maupun tiga materi pendidikan seks secara implisit atau hanya sekedar pembiasaan. Kedua instansi tersebut sudah menerapkan pendidikan seks, hanya saja masih ada beberapa materi pendidikan seks yang belum tercantum dalam perangkat pembelajaran sehingga penerapan pendidikan seks belum dilaksanakan secara optimal.

\section{UCAPAN TERIMA KASIH}

Terima kasih saya kami ucapkan kepada TK Negeri Garuda dan RA Al-Kautsar atas partisipasi dan dukungannya dalam penelitian ini.

\section{DAFTAR PUSTAKA}

Amirudin, A., \& Nirmala, I. (2018). Pendidikan Seksual Anak Usia Dini dalam Persfektif Hukum Islam. (JAPRA) Jurnal Pendidikan Raudhatul Athfal (JAPRA), 1(1), 51-66. https://doi.org/10.15575/japra.v1i1.3546

Andika, A. (2010). Ibu Dari Mana Aku Lahir. Pustaka Grhatama.

Borg, W., \& Gall, M. (1983). Educational Research: An Introduction 4th edition Longman Inc. New York.

Camelia, L., \& Nirmala, I. (2017). Penerapan Pendidikan Seks Anak Usia Dini Menurut Perspektif Islam (Upaya Pencegahan kekerasan dan Pelecehan Seksual Terhadap Anak Usia Dini Melalui Penerapan Pendidikan Seks Dalam Perspektif Sunnah Rasul). Yaa Bunayya: Jurnal Pendidikan Anak Usia Dini, 1(1), 27-32.

Chasanah, I. (2018). Psikoedukasi Pendidikan Seks untuk Meningkatkan Sikap Orangtua dalam Pemberian Pendidikan Seks. Jurnal Intervensi Psikologi (JIP). https://doi.org/10.20885/intervensipsikologi.vol10.iss2.art5

Chomaria, N. (2012). Pendidikan seks untuk anak. Aqwam.

Dacholfany, M. I., \& Hasanah, U. (2018). Pendidikan anak usia dini menurut konsep islam.

Hi.Yusuf, H. (2020). Pentingnya Pendidikan Seks Bagi Anak. Al-Wardah, 13(1), 131. https://doi.org/10.46339/al-wardah.v13i1.163 
Hurlock, E. B. (1978). Perkembangan Anak Jilid 1. (Alih Bahasa: Meitasari Tjandra \& Muslichah Zarkasih). Penerbit Erlangga.

Jatmikowati, T. E., Angin, R., \& Ernawati, E. (2015). Model Dan Materi Pendidikan Seks Anak Usia Dini Perspektif Gender Untuk Menghindarkan Sexual Abuse. Jurnal Cakrawala Pendidikan, 3(3). https://doi.org/10.21831/cp.v3i3.7407

Justicia, R. (2017). Pandangan Orang Tua Terkait Pendidikan Seks Untuk Anak Usia Dini. $\begin{array}{llll}\text { Early Childhood: Jurnal } & \text { 28-37. }\end{array}$ https://doi.org/10.35568/earlychildhood.v1i2.121

Mukti, A. (2018). Pendidikan Seks Untuk Anak Usia Dini Perspektif Islam. Jurnal Harkat: Media Komunikasi Gender, 12(2). https:/ / doi.org/10.15408/harkat.v12i2.7562

Oktarina, N. D., \& Liyanovitasari, L. (2019). Media Cerita Bergambar Tentang Pengenalan Seks Dini Meningkatkan Pengetahuan Anak Usia Dini. Jurnal Kesehatan Perintis (Perintis's Health Journal), 6(2), 110-115. https://doi.org/10.33653/ikp.v6i2.296

Rahmawati, N. (2012). Gambaran Perilaku Seksual Pada Anak Usia Sekolah Kelas 6 Di Tinjau Dari Media Cetak Dan Media Elektronik Sekolah Dasar Negeri 16 Banda Aceh Tahun 2012. Jurnal Kesehatan Masyarakat.

Ratnasari, R. F., \& Alias, M. (2016). Pentingnya Pendidikan Seks untuk Anak Usia Dini. Jurnal Tarbawi Khatulistiwa.

Sarwono, S. W., \& Siamsidar, A. (1986). Peranan orang tua dalam pendidikan seks. Rajawali, Jakarta.

Sujarweni, V. W. (2014). SPSS untuk Penelitian. In SPSS untuk Penelitian.

Susanto, A. (2017). Pendidikan Anak Usia Dini (Konsep dan Teori). Bumi Aksara.

$\mathrm{Wu}, \mathrm{C}$. Y., \& Lee, T. S. H. (2020). Impact of parent-child relationship and sex on trajectories of children internalizing symptoms. Journal of Affective Disorders. https://doi.org/10.1016/j.jad.2019.09.016

Yuniarni, D. (2021). Pengembangan Busy Book Berbasis Neurosains dalam Rangka Pengenalan Seks untuk Anak Usia Dini. Jurnal Obsesi: Jurnal Pendidikan Anak Usia Dini, 6(1), 513-525. https://doi.org/10.31004/obsesi.v6i1.1336 